\title{
JURISPRUDENCIA AMBIENTAL EN CASTILLA-LA MANCHA (SEGUNDO SEMESTRE 2016)
}

\author{
Nuria María GaRrido Cuenca \\ Profesora Titular Derecho Administrativo \\ Universidad de Castilla-La Mancha
}

\begin{abstract}
Sumario: 1.Responsabilidad patrimonial por ataque del lobo como especie protegida a una cabaña ganadera; 2.El control de las inversiones ambientales a efectos impositivos; 3 . El "fuerte viento" como causa de fuerza mayor exonerante de la responsabilidad de la Administración en un parque natural; 4.Procedimiento sancionador iniciado mediante "petición razonada" y exigencia de reposición a su estado anterior de vía pecuaria donde se siembran almendros y se instala riego por goteo; 5.La confirmación por el Tribunal Supremo de la nulidad del estudio informativo y la Declaración de Impacto Ambiental de la conexión de alta capacidad de Toledo y Ciudad Real por la Autovía de los viñedos
\end{abstract}

\section{Responsabilidad patrimonial por ataque del lobo como especie protegida a una cabaña ganadera}

La sentencia de 20 de julio de 2016 del Juzgado de lo Contencioso-Administrativo $\mathrm{n}^{\circ} 1$ de Guadalajara estima parcialmente la demanda formulada por un ganadero de Guadalajara, condenando a la Junta de Comunidades a indemnizarle con 5000 euros para resarcir el ataque de lobos a su cabaña ganadera, que causó la muerte a doce cabras y un ternero. La sentencia estima la concurrencia de los requisitos que dan lugar a la existencia de responsabilidad patrimonial de la Administración, esgrimiendo el carácter de especie protegida del lobo y por tanto su no deber de soportar el daño causado. La solución judicial se ampara en las propias normas autonómicas (en el caso el Decreto 114/2014, de 20 de noviembre) que vienen regulando la concesión directa de ayudas a ganaderos de la Sierra Norte de Guadalajara para paliar los daños producidos por ataques de lobos. Frente a la tesis de la Administración, que entiende exonerada su responsabilidad en base a estas medidas de fomento, el juzgador entiende que no se prevé en la norma la incompatibilidad pretendida, sin presuponer que el acogimiento a las ayudas suponga la renuncia al resarcimiento de daños a cargo de la Administración competente en materia de protección del medio ambiente. Por tanto, se trata de una acción de responsabilidad patrimonial, de naturaleza distinta a las ayudas, perfectamente legítima que tiende en este caso a la reparación integral del daño sufrido. Destaca en la sentencia que el carácter de 
especie protegida del lobo impide a los ganaderos tomar medidas para la defensa de sus bienes, en cumplimiento de la normativa ambiental estatal y autonómica, recayendo en definitiva la responsabilidad en la Administración.

Este pronunciamiento judicial significa un importante precedente jurídico en nuestra Región, abriendo la vía a futuras reclamaciones patrimoniales por parte de decenas de ganaderos de la Sierra Norte de Guadalajara afectados por los constantes ataques de lobos y buitres al ganado.

Aunque hay que señalar que ya existe jurisprudencia tanto del Tribunal Supremo como del Tribunal Superior de Justicia de Castilla-León coincidentes en la resolución de casos similares en aquella comunidad autónoma. Como por ejemplo la Sentencia del Tribunal Superior de Justicia de Castilla y León, 187/2015, de 4 de diciembre (JUR 2016120796), que también entendió que concurrían los requisitos exigidos legal y jurisprudencialmente para declarar la responsabilidad patrimonial de la Administración demandada, pues los daños ocasionados por el lobo, como especie protegida, no deben ser soportados de forma individual, sino que corresponde a la Administración su resarcimiento (vid la cita de la jurisprudencia sobre el particular en esta sentencia).

\section{El control de las inversiones ambientales a efectos impositivos}

La Sentencia del Tribunal Superior de Justicia de Castilla-La Mancha, (Sala de lo Contencioso-Administrativo, Sección 1ª), nº 119/2016 de 23 mayo (JUR\2016\187203) resuelve sobre una Resolución de la Consejería de Agricultura de la Junta de Comunidades de Castilla-La Mancha, que desestimó el recurso de alzada frente a la denegación de solicitud de certificación de convalidación de la inversión medioambiental en una planta de residuos de Manzanares. La Administración había entendido que el objeto de las inversiones era simplemente cumplir con las condiciones impuestas en la autorización ambiental integrada, reputando inexistente la mejora de las exigencias de la normativa de protección del medio ambiente atmosférico que hubiera podido suponer una reducción en la cuota del impuesto de sociedades.

El Tribunal ratifica que, efectivamente, las deducciones por inversiones de tipo medioambiental están previstas en el art.39 de la Ley del Impuesto sobre Sociedades 
(Real Decreto Legislativo 4/2004, de 5 de marzo, en su redacción dada por la modificación que llevó a cabo la Ley 2/2011, de 4 de marzo), que dispone:

1. Las inversiones realizadas en bienes del activo material destinadas a la protección del medio ambiente consistentes en instalaciones que eviten la contaminación atmosférica o acústica procedente de instalaciones industriales, o contra la contaminación de aguas superficiales, subterráneas y marinas, o para la reducción, recuperación o tratamiento de residuos industriales propios, siempre que se esté cumpliendo la normativa vigente en dichos ámbitos de actuación pero se realicen para mejorar las exigencias establecidas en dicha normativa, darán derecho a practicar una deducción en la cuota íntegra del 8 por ciento de las inversiones que estén incluidas en programas, convenios o acuerdos con la Administración competente en materia medioambiental, quien deberá expedir la certificación de la convalidación de la inversión.

$[\ldots]$

4. La parte de la inversión financiada con subvenciones no dará derecho a deducción.

La Administración admitió, en la resolución del recurso de alzada, que las medidas adoptadas por la empresa podrían redundar en un beneficio ambiental, pero que el precepto legal exigía no sólo cumplir con la normativa medioambiental, sino que para poder practicarse la deducción habría de acreditarse una mejora de las exigencias previstas en dicha normativa. Ese plus sobre la necesaria observancia de las normas medioambientales es lo que daría pie a una posible deducción en el impuesto sobre sociedades, que no había sido probada en el caso de autos.

El Tribunal compartirá la tesis de la Administración, pues aunque efectivamente las inversiones realizadas supusieron que los valores de emisión de plomo y partículas se habían reducido respecto a los valores límites establecidos por la autorización ambiental integrada, la mejora para el medio ambiente tendría que partir de una previa observancia de la normativa vigente. Y que sólo obtenida la certificación de convalidación de las inversiones medioambientales podría entrar en juego la normativa tributaria. Según los informes, las inversiones que llevó a cabo la parte actora eran necesarias, imprescindibles, para cumplir con las condiciones que le habían sido impuestas por la autorización ambiental integrada; realizadas las inversiones, ciertamente disminuyeron las emisiones por debajo de los máximos tolerados, pero ello no permite concluir que las mejoras podían ser certificadas a los efectos tributarios queridos. 
En definitiva, el Tribunal realiza una interpretación de los preceptos y hechos discutidos en el sentido de que se debe partir de una situación en la que ya se esté cumpliendo la normativa vigente y las inversiones se realicen para mejorar esas exigencias que ya se estaban observando. Lo que no ampara la situación en la que, al hilo de invertir para poder cumplir con la normativa -la cual no se estaba cumpliendo en ese particular-, se consiga una mejora en materia medioambiental. Concluirá la sentencia: “...Devendría ilógico "premiar" con una certificación de convalidación de inversiones medioambientales que luego se traduciría en deducciones fiscales a quien se hubiera limitado a realizar inversiones para cumplir la normativa, que antes no cumplía, por la sola realidad de que lo invertido se hubiese traducido en una mejora medioambiental”.

\section{El "fuerte viento" como causa de fuerza mayor exonerante de la responsabilidad de la Administración en un parque natural}

La Sentencia 194/2016, de 24 de junio del Juzgado de los contencioso-administrativo n$^{\circ} 1$ de Toledo resuelve el recurso interpuesto por la aseguradora MAPFRE en concepto de responsabilidad patrimonial por los daños producidos en un vehículo cuando se encontraba estacionado en un Parque forestal de titularidad autonómica y le cayó un árbol encima. La Administración entendió que en este accidente había concurrido fuerza mayor, por un fuerte temporal de viento, que excluiría su responsabilidad. No se discute en el caso que efectivamente en este entorno existían este y otros árboles en estado de mala conservación, como demuestran los informes periciales, ni la propia existencia del daño producido. Lo que se discute es si, por concurrir fuerza mayor, debe quedar exonerada la Administración de responder, en un supuesto en el que concurren todos los restantes elementos determinantes de la responsabilidad patrimonial de la Administración, con el consecuente deber de la demandante de soportar del daño sufrido, partiendo de que, a quien incumbe la carga de la prueba de la fuerza mayor exonerante es, por supuesto, a quien la alega y por tanto a la Administración.

El juzgador repasará la muy discutida catalogación del fuerte viento como causa de fuerza mayor, en relación con este tipo de siniestros, en una jurisprudencia muy casuística e incluso contradictoria. Cita la STSJ Andalucía de 26 de noviembre de 2008 (recurso 1234/2002) que entendió que un viento superior a 83 Km exoneraba de responsabilidad de la Administración; sin embargo, la STSJ Andalucía de 5 de noviembre de 2008 
(recurso 2007/2002 ), atribuyó la culpa a la Administración, incluso con estas rachas de viento, por entender la omisión en la conservación adecuada de los árboles; en otros casos se ha tenido en cuenta las prevenciones establecidas en la normativa de seguridad (por ejemplo, contra rotura de cables y de sus apoyos, STSJ Canarias de 1 de abril de 2009); o si el viento es una circunstancia habitual en la zona o incluso las previsiones climatológicas lo han advertido (STSJ País Vasco, de 19 de febrero de 2009).

En el caso que comentamos, según los informes aportados a la causa, la racha máxima de viento fue de $57 \mathrm{KM} /$ hora, que "no puede considerarse ni imprevisible, ni insólita, ni extraordinaria, ni, en definitiva, constitutiva de la fuerza mayor invocada". Terminará la sentencia estimando el recurso y declarando la responsabilidad patrimonial de la Administración.

\section{Procedimiento sancionador iniciado mediante "petición razonada" y exigencia de} reposición a su estado anterior de vía pecuaria donde se siembran almendros y se instala riego por goteo.

La Sentencia 413/2016, de 22 de junio, del Tribunal Superior de Justicia de Castilla La Mancha (rec. No390/2014) resuelve sobre la legalidad de un procedimiento sancionador frente a la plantación de almendros y riego por goteo en una superficie de dominio público pecuario, imponiendo una sanción y como medida complementaria la reposición de la vía pecuaria consistente en retirar la nueva plantación y el riego, que no había sido autorizada.

La primera apreciación del Tribunal será la de declarar la infracción de los principios del procedimiento sancionador, constatando que el inicio de éste a través de un informe llamado "de afección a la Cañada de la Mancha", firmada por técnicos de la Delegación de Agricultura dela Junta de Comunidades en Albacete, pero sin expresar quienes fueron los técnicos o funcionarios que realizaron la visita, la situación de los almendros si dentro o fuera de la zona deslindada y los datos necesarios para poder apreciar la antiguiedad de la plantación, incumple el art.11.1.c) del RD 1398/93, que establece, como es sabido, que: “1. Los procedimientos sancionadores se iniciarán siempre de oficio, por acuerdo del órgano competente, bien por propia iniciativa o como consecuencia de orden superior, petición razonada de otros órganos o denuncia [...] c) Petición razonada: La propuesta de iniciación del procedimiento formulada por cualquier órgano administrativo que no tiene competencia para iniciar el procedimiento y que ha tenido conocimiento de las conductas 
o hechos que pudieran constituir infracción, bien ocasionalmente o bien por tener atribuidas funciones de inspección, averiguación o investigación. Las peticiones deberán especificar, en la medida de lo posible, la persona o personas presuntamente responsables; las conductas o hechos que pudieran constituir infracción administrativa y su tipificación; así como el lugar, la fecha, fechas o período de tiempo continuado en que los hechos se produjeron".

Con apoyo en una sólida jurisprudencia, el Tribunal entenderá que existe un defecto importante en el procedimiento sancionador, pues las exigencias normativas se hacían necesarias e ineludibles más cuando la actora a través de sus alegaciones y recurso de alzada había reiterado su indefensión, sin permitirle aportar las pruebas y testimonios necesarios para demostrar la antigüedad de la plantación de los almendros y la situación de los mismos.

El Tribunal se apoya en la sentencia 143/2015, de 8 de octubre, del Juzgado de Primera Instancia $\mathrm{n}^{\mathbf{0}} 4$ de Albacete que desestima la demanda de acción declarativa de dominio de la actora con relación a los terrenos donde se encontraban los almendros plantados, reconociendo que se encontraban dentro de la zona de dominio público de la vía pecuaria perjudicando a la Cañada. Sin embargo, no hay pruebas ni informes que permitan concretar la fecha de la plantación para poder declarar o no prescrita la infracción. Por estos defectos formales en la iniciación del procedimiento sancionador el Tribunal termina declarando la nulidad de la sanción.

No ocurre lo mismo respecto a la obligación de retirada de los almendros y reposición a su estado originario de la calzada, pues habiéndose demostrado su ubicación en zona de dominio público pecuario, resulta imprescriptible ex art. 132.1 CE. Entenderá el Tribunal que la nueva plantación no tenía por fin la conservación y mantenimiento de la plantación antigua, sino mejorar la finca y su capacidad productiva. Por ello esta conducta se encuadraría la infracción prevista en la Ley 9/2003, de vías pecuarias referida a "la roturación o plantación no autorizada que se realice en cualquier clase de vía pecuaria". En definitiva, se estimará en parte el recurso, anulando la multa impuesta, pero manteniendo la orden de reposición. 


\section{La confirmación por el Tribunal Supremo de la nulidad del estudio informativo y la Declaración de Impacto Ambiental de la conexión de alta capacidad de Toledo y Ciudad Real por la Autovía de los viñedos}

Aunque no se trate de una sentencia dictada por uno de nuestros tribunales autonómicos, nos ha parecido relevante dar noticia en estas Crónicas de la Sentencia del Tribunal Supremo n¹702/2016, de 11 de julio (RJ\201613894) que resuelve el recurso de casación interpuesto por la Junta de Comunidades frente a la STSJCM de 27 de febrero de 2015 (PROV 2015, 89173), que anuló la Resolución de la Consejería de Ordenación del Territorio y Vivienda que aprobaba el estudio informativo de la conexión de alta capacidad de Toledo y Ciudad Real por la Autovía de los Viñedos, y su Declaración de Impacto Ambiental.

En síntesis, la doctrina de nuestro Tribunal se basó para declarar la nulidad del acto administrativo en los siguientes argumentos:

$1^{\circ}$ ) que el proyecto contempla una carretera que discurre por el territorio de la Comunidad, enlazando dos capitales de provincia de nuestra Autonomía con intereses de todo tipo en esa conexión, y por tanto su construcción es competencia exclusiva autonómica, frente al alegato de que pudiera estarse ante una infraestructura de interés general. El TSJCM entiende que el proyecto entra dentro de las competencias autonómicas, siendo cuestión distinta que su entramado pueda estar conectado a la red de carreteras del Estado y aprovechado por éste para articular adecuadamente las distintas vías de comunicación del territorio nacional, que atiendan y respondan a las necesidades del tráfico, el transporte y la economía de nuestro país. Por ello tampoco cree el Tribunal que el proyecto responda a un supuesto y velado interés de fragmentar un proyecto global más amplio de comunicación de nuestra comunidad con la de Andalucía o el resto de España con el fin de evitar a través del troceado de la obra una declaración de impacto global que teniendo en cuenta todo el trazado de la obra sería más exigente desde el punto de vista medioambiental, mientras que mediante la fragmentación de la obra se conseguirían declaraciones medioambientales parciales más permisivas y generosas al contemplar los daños en áreas más restringidas y no en toda la gran dimensión de la obra acometida.

El TSJ no entendió como prueba bastante para sostener que esta obra sea un tramo de la proyectada autovía de peaje Toledo-Ciudad Real-Córdoba N-IV, fundamentalmente porque ese proyecto más amplio tuvo que ser abandonado, entre otras razones, como consecuencia de la Declaración Ambiental de carácter negativo en 2007. De ahí que se 
emprenda otro nuevo proyecto, distinto al estatal, que sortea algunas áreas de protección perjudicadas por el anterior proyecto y aprovecha el trazado de la Autovía de los Viñedos y de la N-401. Sin embargo, el proyecto enjuiciado transcurre por las principales zonas que ya la Declaración negativa del Estado señaló en 2007 (y que llega a corroborar un informe de la propia Consejería): "es una prueba importante para demostrar la significativa afección que una obra similar y con un trazado equivalente que atravesaba la ZEPA y LIC de Montes de Toledo, también afectados por el presente proyecto ahora enjuiciado, causaban a esas zonas de especial protección medioambiental en cuanto a las especies de fauna ya señaladas como son el lince ibérico, el águila imperial, el buitre y la cigüeña negra, con planes de recuperación específicos en evitación de su posible extinción. Las afirmaciones contenidas en el informe desmienten la tesis y posicionamiento defendidos por la Junta de Comunidades en su contestación de que estemos ante daños o peligros que no son realmente significativos; al contrario según dicho informe son relevantes y muy peligrosos".

$2^{\circ}$ ) No se ha elegido la alternativa más beneficiosa para los intereses ambientales, que deben primar sobre los puramente económicos. Importantísimo razonamiento del TSJ en la ponderación de intereses implicados que llevará a sustentar de manera inequívoca la nulidad del proyecto. En efecto, aplicando el art. al art. 6.4 de la Directiva 92/43/CEE, se concluye que si existen soluciones alternativas para la ejecución del proyecto que no causan daño ambiental esa debería ser la opción preferente. En el asunto el TSJ entiende que de las cuatro opciones barajadas se ha elegido una perjudicial para especies protegidas como lo es la 1; existiendo la 4 que no es nociva o inocua debería haber sido ésta calificada como la mejor. Así además se demostró en la pericial practicada y en la propia DIA impugnada, como la que menor incidencia causaría en la Red Natura 2000. A juicio de la Sala "basta que se haya barajado esta alternativa, debidamente evaluada, como una de las posibles para la ejecución del proyecto, para que hubiese debido ser preferida como la más correcta para la ejecución del proyecto a la vista de la incidencia negativa que tenía la $\mathrm{n}^{\circ} 1$ sobre valores ecológicos y faunísticos". Las razones ofrecidas por la Administración autonómica sobre su mayor coste económico (ya que alarga el trazado o itinerario en $30 \mathrm{~km}$, y ni ahorra tiempo ni mejora la seguridad vial) "no deben prevalecer sobre unos superiores como son los ecológicos legalmente protegidos".

$3^{\circ}$ ) Rechazo de una imperiosa razón de salud o seguridad pública El TSJ tampoco aprecia que se justifique la existencia de la excepción normativa prevista para alternativas menos 
viables ambientalmente que afectan a una ZEPA. Primero porque no se han cumplido las exigencias formales de su declaración por ley o acuerdo del Consejo de Ministros o del órgano de gobierno de la Comunidad Autónoma, que en este caso en ningún momento se han acreditado. Para el caso del LIC tampoco se han acreditado esas formalidades ni que existieses en imperiosas razones de salud o seguridad pública o cualquiera otra de interés público de primer orden. La única justificación que se ofreció para la realización del proyecto fue que la conexión Ciudad Real Toledo a través de la N-401 "genera importantes problemas de tráfico en las travesías anteriormente citadas y no atiende a la demanda de desplazamientos entre Toledo y Ciudad Real y localidades al Norte de ésta; actualmente utilizan la saturada Autovía A-4 para este fin" y que "la redacción del Estudio Informativo de la conexión en alta capacidad de Toledo y Ciudad Real por la Autovía de los Viñedos pretende crear una vía que satisfaga la demanda de desplazamientos entre ambas poblaciones con un considerable ahorro de tiempo con relación a la situación actual, aumento de la accesibilidad de la zona, mejora de la funcionalidad y unas condiciones de seguridad vial superior". Para el TSJ, se trata de justificaciones que sin gran esfuerzo argumental se pueden desterrar como afines a los intereses generales o públicos superiores de primer orden exigidos legalmente que puedan avalar la bondad y viabilidad del proyecto en este caso perjudicial para la fauna protegida.

El Tribunal Supremo confirmará en todos sus extremos estos argumentos del tribunal de instancia, quedando reducido el caso a una mera cuestión de prueba que, como bien se argumenta, no puede ser objeto de revisión en sede casacional, a menos que se demuestre su arbitrariedad o error, lo que en el caso no sucede. 